\title{
Automatic Multi-Objective Calibration of a Rainfall Runoff Model for the Fitzroy Basin, Queensland, Australia
}

\author{
Md. Sharif Imam Ibne Amir, Mohammad Masud Kamal Khan, Mohammad Golam Rasul, Raj H. \\ Sharma, and Fatema Akram
}

\begin{abstract}
This paper presents a large scale hydrological model for the Fitzroy Basin using the MIKE 11 NAM modelling system. This model simulates the rainfall runoff processes for the three different and interrelated storages which are surface storage, root zone storage and groundwater storage. The parameters of such model cannot be obtained directly from measurable quantities of catchment characteristics. Hence model calibration is required to get the model parameters. Manual calibration is very time consuming and it only focuses on a single objective function. Thus tradeoff exists between the different objectives. For this study, an automatic calibration was done considering the four multiple objectives and obtained the optimal values of the model parameters for each catchment. The simulated and observed discharge hydrographs show a reasonable good match for each sub-catchment. Moreover model reliability was evaluated using the statistical methods Index of Agreement (IA) and Efficiency Index (EI). The IA and EI obtained 0.821-0.951 and 0.849-0.961 for different sub-catchments.
\end{abstract}

Index Terms-Basin, catchment, calibration, hydrological model, MIKE 11 NAM.

\section{INTRODUCTION}

Assessment of runoff from a catchment is very important for hydrologic analysis, water resources planning, integrated hydrology-hydraulic model development, flood studies and many other applications. A hydrologic model is a practical tool for estimation of catchment runoff. Hydrologic models can be classified as conceptual and physically based according to the physical processes involved in modelling [1]. In physically based model the detail physical processes can be represented in a deterministic way by the representations of mass, momentum and energy conservation where as in conceptual models each of the hydrologic processes are represented by simplified mathematical relationships [2]. According to the spatial description of the watershed process, hydrologic models can be classified as lumped or distributed. In a distributed model the spatial variability of vegetation, soil, topography, etc. is taken into account, while in a lumped model the spatial variability of watershed characteristics is ignored. The conceptual models are usually lumped while the physically based model in practice has to be distributed [3].

Manuscript received January 5, 2013; revised March 14, 2013.

M. S. I. I. Amir and F. Akram are with the Centre for Plant and Water Science, Central Queensland University, Rockhampton, QLD 4702, Australia (e-mail: m.amir@cqu.edu.au, f.akram@cqu.edu.au).

M. M. K. Khan, M. G. Rasul, and R. H. Sharma are with the School of Engineering and Technology, Central Queensland University, Rockhampton, QLD 4702, Australia (e-mail: m.khan@cqu.edu.au,m.rasul@cqu.edu.au, r.sharma@cqu.edu.au).
Distributed hydrologic models require huge data and model parameter identification that may limit their strength and their adequacy for operational purposes. In addition, there is no clear proof that distributed models contribute additional model efficiency. Therefore the use of lumped RR models still remains a valuable alternative as these models use well established physical laws at micro scale (such as Penman's potential evaporation model, Richard's infiltration equation, etc.).

The MIKE 11 NAM model [4]-[5], the HEC-HMS model [6], the RORB model [7], the XP-RAFTS model [8], the Tank model [9], and the Sacramento model [10] are the examples of the lumped hydrologic model. In these models the parameters cannot be obtained directly from measurable quantities of catchment characteristics. Therefore the model calibration is essential. In the calibration process model parameters are estimated so that the model can simulate the hydrological behavior of the catchment as closely as possible [11]. A model calibration can be classified as manual or automatic. In manual calibration a trial-and error parameter adjustment is done based on a visual judgment by comparing the observed and the simulated discharge. It is very difficult to obtain a very good and hydrologically sound model by manual calibration as it involves the judgment of the modeller. Besides, it is very time consuming for an inexperienced hydrologist. On the other hand, in automatic calibration a computer based automatic procedure is applied to adjust the model parameters. In the automatic calibration the confidence of the model simulation can be explicitly stated and calibration process is very fast compared to manual calibration [12]. However single object function based automatic calibration is often insufficient to properly measure the simulation of all the important characteristics of a catchment [13]. Therefore multi-objective calibration procedure is very important for hydrological modelling.

The objective of the present study is to estimate the rainfall runoff discharges for the large Fitzroy Basin by using a conceptual rainfall runoff model, the MIKE 11 NAM, considering the multi-objective calibration. The multiple objective criteria are described in the "Material and Method" section. The model simulation was carried out for the period from 1972 to 2011. The automatic calibration was performed and hydrological model parameters were determined for each sub-catchment. The simulated and observed discharge hydrographs show a reasonable match. The output of this hydrological model was used to develop a full one-dimensional hydrodynamic module to calculate flow propagation for the complex and long river system of the Fitzroy Basin. 


\section{MATERIAL AND METHOD}

\section{A. Study Area}

The study area is the Fitzroy Basin, which is located in the east part of Queensland, Australia (Fig. 1). This area lies geographically between latitude $21^{\circ} \mathrm{S}$ and $27^{\circ} \mathrm{S}$ and longitude $147^{\circ} \mathrm{E}$ and $151^{\circ} \mathrm{E}$ [14]. The Fitzroy river catchment covers an area of $144,000 \mathrm{~km}^{2}$ [14]. A total of 6 sub-catchments have been defined based on six major rivers of this basin. All of the sub-catchments are presented in Fig. 1.

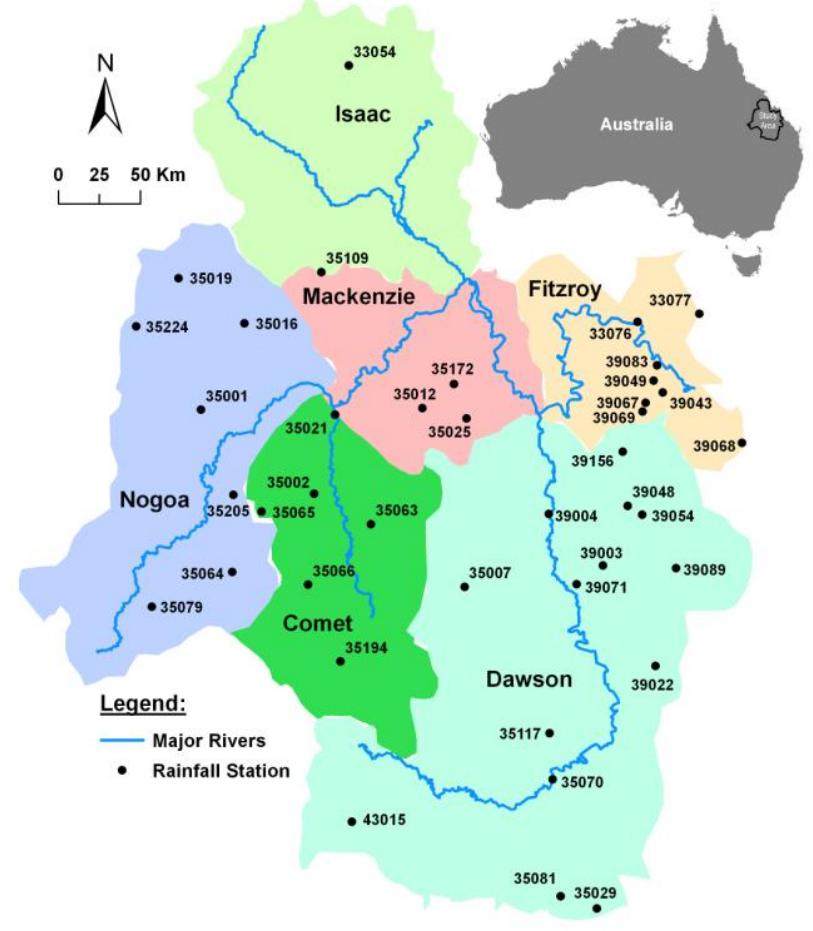

Fig. 1. Fitzroy Basin

\section{B. Data}

The historical daily time series data of rainfall and evaporation for the period 1972 to 2011 have been used to develop this model. The data have been provided by the Bureau of Meteorology (BoM), Australia. For this study, data of 40 rainfall stations and 4 evaporation stations were selected based on minimum missing records. There were no daily evaporation data in the two sub-catchments. Data from neighboring sub-catchments were used for the missing sub-catchments. Besides, there were some missing records during the selected period for rainfall and evaporation data. The missing data were filled up by applying the Arithmetic Mean Method [15]. The mean area weights or proportion of rainfall that a station contributes to each of the sub-catchment were determined using the Thiessen Polygon method and are presented in Table I.

The basic input requirements of the NAM model are given below.

- Catchment information (identification of catchments, area of the catchments, basin composition of catchment)

- Meteorological data (rainfall and potential evaporation)

- Hydrological data (discharge at the outlet of the catchments for model calibration and validation)

- Model parameters (time constants and threshold values for routing surface storage, rootzone storage and groundwater storage)

\section{Model Description}

The hydrological model, MIKE 11 NAM was applied in this study. NAM is a Danish word and the full abbreviation is "Nedbør-Afstrømings-Model", "precipitation-runoff-model". meaning

Hydrodynamics and Water Resources of the Technical University of Denmark was developed this model first [4]. The well-proven hydrological model NAM is widely used all over the world for different climate regimes [16].

The NAM model structure is shown in Fig. 2. The NAM model simulates the rainfall-runoff processes occurring in a single catchment or several catchments in a river basin. NAM is a rainfall-runoff module of MIKE 11 river modelling system. It can be applied independently or used to represent one or more contributing catchments that generate lateral inflows to a river network. NAM is a deterministic, lumped, conceptual model. In deterministic model, two separate simulations with the same input under identical conditions will always give the same result. Being a lumped model, each catchment is regarded as one unit and parameters are averaged. Being a conceptual model NAM is based on considerations of the physical processes. The NAM model represents three different and interrelated storages which are: 1) surface storage, 2) lower zone or root zone storage, and 3) groundwater storage. In the automatic calibration process the nine key parameters of the NAM model were determined that is presented in Table II.

TABLE I: WEIGHT OF RAINFALL STATION TO COMPUTE MEAN RAINFALL OF SUB-CATCHMENTS

\begin{tabular}{lll}
\hline \hline Sub-catchments & Rainfall stations & Respective weight \\
\hline Isaac & 33054,35109 & $0.59,0.41$ \\
\hline \multirow{2}{*}{ Comet } & $35002,35021,35063,35065$, & $\begin{array}{l}0.11,0.09,0.24,0.06, \\
0.17,0.33\end{array}$ \\
\hline \multirow{2}{*}{ Nogoa } & 35066,35194 & $0.19,0.17,0.09,0.11$, \\
& $35001,35016,35019,35064$, & $0.27,0.11,0.07$ \\
\hline \multirow{2}{*}{ Mackenzie } & $35079,35205,35224$ & $0.47,0.14,0.40$ \\
\hline \multirow{2}{*}{ Dawson } & $35012,35025,35172$ & $0.12,0.03,0.11,0.07$, \\
& $35007,35029,35070,35081$, & $0.11,0.03,0.10,0.07$, \\
& $35117,39003,39004,39022$, & $0.02,0.03,0.06,0.07$, \\
\hline \multirow{2}{*}{ Fitzroy } & $39048,39054,39071,39089$, & $0.04,0.15$ \\
& 39156,43015 & $0.43,0.06,0.09,0.03$, \\
\hline \hline
\end{tabular}

TABLE II: MiKe 11 NAM MODEL PARAMETERS (SOURCE: [17])

\begin{tabular}{|c|c|c|c|}
\hline Parameter & Description & $\begin{array}{l}\text { Lower } \\
\text { bound }\end{array}$ & $\begin{array}{l}\text { Upper } \\
\text { bound }\end{array}$ \\
\hline $\begin{array}{l}\text { Umax } \\
(\mathrm{mm})\end{array}$ & $\begin{array}{l}\text { Maximum water content in surface } \\
\text { storage }\end{array}$ & 5 & 35 \\
\hline $\begin{array}{l}\mathrm{Lmax} \\
(\mathrm{mm})\end{array}$ & $\begin{array}{l}\text { Maximum water content in root } \\
\text { zone storage }\end{array}$ & 50 & 350 \\
\hline CQOF & Overland flow runoff coefficient & 0 & 1 \\
\hline CKIF (h) & Time constant for interflow & 500 & 1000 \\
\hline TOF & $\begin{array}{l}\text { Root zone threshold value for } \\
\text { overland flow }\end{array}$ & 0 & 0.9 \\
\hline $\mathrm{CK}_{1,2}(\mathrm{~h})$ & $\begin{array}{l}\text { Time constant for routing overland } \\
\text { flow }\end{array}$ & 3 & 72 \\
\hline TIF & $\begin{array}{l}\text { Root zone threshold value for inter } \\
\text { flow }\end{array}$ & 0 & 0.9 \\
\hline TG & $\begin{array}{l}\text { Root zone threshold value for } \\
\text { ground water recharge }\end{array}$ & 0 & 0.9 \\
\hline $\mathrm{CK}_{\mathrm{BF}}(\mathrm{h})$ & $\begin{array}{l}\text { Time constant for routing base } \\
\text { flow }\end{array}$ & 500 & 1000 \\
\hline
\end{tabular}




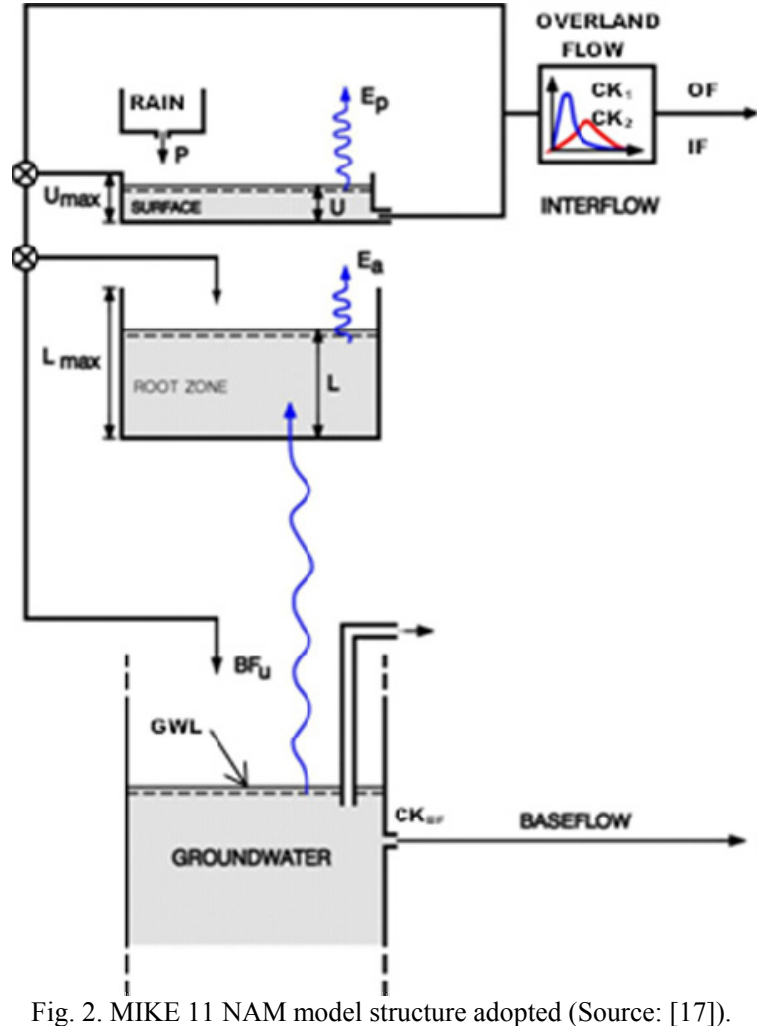

Fig. 2. MIKE 11 NAM model structure adopted (Source: [17]).

The rainfall-runoff estimation from the MIKE 11 NAM model can be divided in two stages. Best possible values of nine model parameter values were estimated using the automatic calibration process in the first stage. Then the model was simulated using the optimum model parameter values.

\section{Multi-Objective Calibration}

It is required to devise the calibration objectives in order to achieve a successful automatic calibration by using multiple objectives in MIKE 11 NAM. There are four objective functions in the NAM model. Madsen [13] described the computational procedure and theoretical justification of these four objective functions which are as follows.

1) Overall volume error (Agreement between the average observed and simulated catchment runoff)

2) Overall root mean square error (Overall agreement of the shape of the hydrograph)

3) Average root mean square error of peak flow events

4) Average root mean square error (RMSE) of low flow events

The goodness-of-fit of the simulated hydrograph is a transformed and normalised measure of the overall RMSE which is based on Coefficient of Determination $\left(R^{2}\right) . R^{2}$ is defined as follows:

$$
R^{2}=1-\frac{\sum_{i=1}^{N}\left(Q_{o b s, i}-Q_{s i m, i}\right)^{2}}{\sum_{i=1}^{N}\left(Q_{o b s, i}-\bar{Q}_{o b s}\right)^{2}}
$$

where $\mathrm{Q}_{\mathrm{obs}}=$ observed value, $\mathrm{Q}_{\text {sim }}=$ simulated values and $\overline{\mathrm{Q}}_{\mathrm{obs}}=$ mean value of observed flow.

\section{E. Model Performance}

The performance of the model depends on the quality of model output. The output of the hydrological model is usually the discharge. The hydrological model can be assessed by visual inspection of graphical plots or statistical methods. The MIKE 11 NAM model performance was evaluated by the statistical method, Index of Agreement (IA), which was defined by Willmott [17]. IA value varies from 0 to 1 with 1 signifying the perfect agreement between simulated and observed values and 0 indicates no agreement at all. Efficiency Index (EI) was another hydrological model assessor as described by Nash and Sutcliffe [18] which had been widely used to detect the model error for the long term simulation. The EI was developed to evaluate the percentage of accuracy of the simulated values with respect to their observed values. EI values equal to 1 signifies the accurate performance of the model. The IA and EI are defined as:

$$
\begin{aligned}
& I A=1-\frac{\sum_{i=1}^{N}\left(Q_{o b s, i}-Q_{s i m, i}\right)^{2}}{\sum_{i=1}^{N}\left(\left|Q_{s i m, i}-\bar{Q}_{o b s}\right|+\left|Q_{o b s, i}-\bar{Q}_{o b s}\right|\right)^{2}} \\
& E I=\frac{\sum_{i=1}^{N}\left(Q_{o b s, i}-\bar{Q}_{o b s}\right)^{2}-\sum_{i=1}^{N}\left(Q_{o b s, i}-Q_{s i m, i}\right)^{2}}{\sum_{i=1}^{N}\left(Q_{o b s, i}-\bar{Q}_{o b s}\right)^{2}}
\end{aligned}
$$

\section{RESUlt AND DiscUSSION}

Accurate stream flow prediction is the main check of any rainfall runoff model. A comparison of observed and simulated stream flow data for the Fitzroy sub-catchment at the Gap gauge location during the calibration period is presented in Fig. 3. A reasonably good calibration was achieved which shows the ability of the model to predict stream flow. The overall trend is captured well by the model. Fig. 4 shows the comparison of simulated and observed discharge data during the past three flood event. The comparison indicates a good match of simulated data with the observed data.

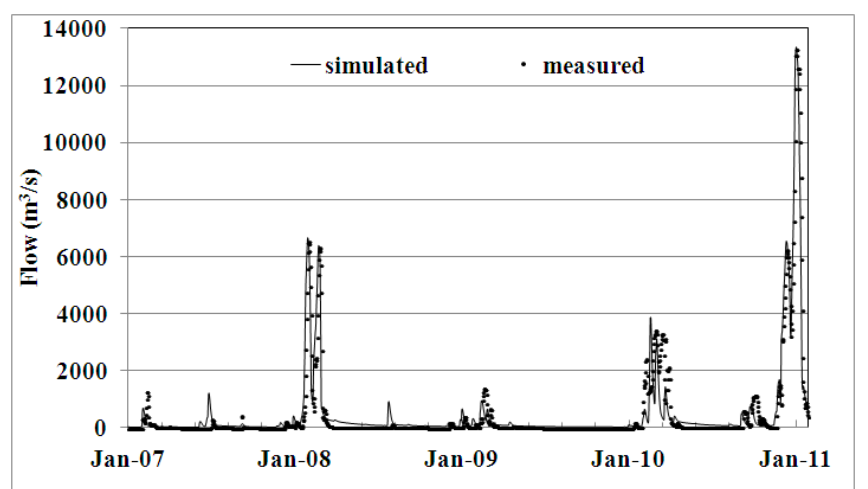

Fig. 3. Daily flow of Fitzroy sub-catchments at Gap station during calibration period.

The model was first calibrated for a 5 year period from $1^{\text {st }}$ January 2007 to $31^{\text {st }}$ January 2011, and then it was validated for another 5 year period from $1^{\text {st }}$ January 1987 to $31^{\text {st }}$ December 1991. The statistical and hydrology specific indicators IA and EI values obtained during the calibration and validation period for the six sub-catchments of Fitzroy Basin are presented in Table III. The automatic calibration yielded $\mathrm{R}^{2}$ and \%WBL (water balance error) values are 
presented in Table IV. "Reference [19] shows that the hydrological model is valid when $\mathrm{R}^{2}>0.80$ and $\% \mathrm{WBL}<$ $10 \%$ ". From the Table IV it is clear that these two values meet the criteria for all sub-catchments.

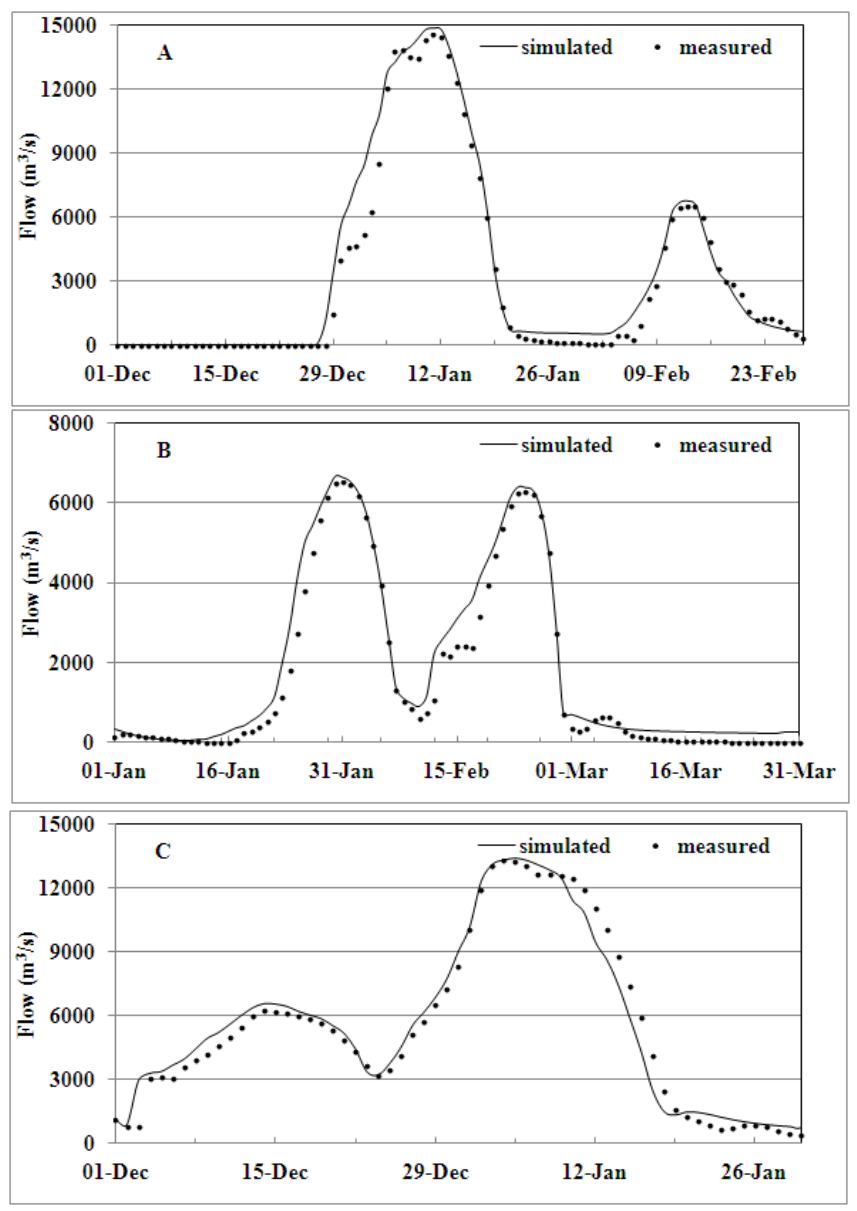

Fig. 4. Daily flow of Fitzroy sub-catchments at Gap station: A) 1991 flood event, B) 2008 flood event, C) 2011 flood event.

TABLE III: Evaluation OF MOdel PeRformance By Statistical METHOD

\begin{tabular}{lllll}
\hline \hline \multirow{2}{*}{$\begin{array}{l}\text { Sub-catchment } \\
\mathrm{s}\end{array}$} & \multicolumn{2}{l}{$\begin{array}{l}\text { Calibration period (1 Jan } \\
\text { 2007-31 Jan 2011) }\end{array}$} & \multicolumn{2}{l}{$\begin{array}{l}\text { Validation period (1 Jan } \\
\text { 1987-31 }\end{array}$} \\
\cline { 2 - 5 } & EI & IA & EI & IA \\
\hline Isaac & 0.953 & 0.891 & 0.878 & 0.846 \\
Nogoa & 0.961 & 0.951 & 0.927 & 0.902 \\
Comet & 0.934 & 0.879 & 0.852 & 0.832 \\
Mackenzie & 0.938 & 0.864 & 0.849 & 0.821 \\
Dawson & 0.947 & 0.886 & 0.863 & 0.838 \\
Fitzroy & 0.951 & 0.889 & 0.889 & 0.837 \\
\hline \hline
\end{tabular}

TABLE IV: AUTOMATIC CALIBRATION AND VALIDATION PARAMETERS

\begin{tabular}{lll}
\hline \hline Sub-catchments & $\mathrm{R}^{2}$ & $\% \mathrm{WBL}$ \\
\hline Isaac & 0.904 & 0.5 \\
Nogoa & 0.912 & 0.2 \\
Comet & 0.844 & 3.8 \\
Mackenzie & 0.821 & 8.4 \\
Dawson & 0.894 & 1.6 \\
Fitzroy & 0.902 & 0.6 \\
\hline \hline
\end{tabular}

The main objective of this study was to get the optimum values of the nine model parameters of the six sub-catchments of the Fitzroy Basin using the four objective functions. These optimum model parameter values represent the runoff coefficient for a particular sub-catchment. The optimum model parameters values of the six sub-catchments are presented in Table $\mathrm{V}$. These optimum values will be used to set up an integrated hydrologic and hydraulic model.

TABLE V: Optimum Mike 11 NAM MOdel PARAMETERS VALUE FOR ALL SUB-CATCHMENTS OF FITZROY BASIN

\begin{tabular}{lllllll}
\hline \hline Parameter & Isaac & Nogoa & Comet & Mackenzie & Dawson & Fitzroy \\
\hline $\mathrm{U}_{\max }$ & 17.1 & 14.8 & 19.3 & 10.6 & 19.1 & 18.4 \\
$\mathrm{~L}_{\max }$ & 179 & 201 & 249 & 104 & 193 & 248 \\
$\mathrm{CQOF}$ & 0.99 & 0.39 & 0.70 & 0.94 & 0.68 & 0.84 \\
$\mathrm{CKIF}$ & 237 & 484 & 263 & 661 & 286 & 251 \\
$\mathrm{CK}_{1,2}$ & 49.3 & 49.8 & 48.9 & 49.4 & 48.8 & 49.5 \\
$\mathrm{TOF}$ & 0.20 & 0.12 & 0.59 & 0.0073 & 0.156 & 0.0912 \\
$\mathrm{TIF}$ & 0.02 & 0.48 & 0.05 & 0.0532 & 0.223 & 0.0157 \\
$\mathrm{TG}$ & 0.16 & 0.776 & 0.646 & 0.0122 & 0.0597 & 0.0089 \\
$\mathrm{CK}$ & 1789 & 3528 & 2509 & 1060 & 1362 & 1109 \\
\hline \hline
\end{tabular}

\section{ACKNOWLEDGMENT}

The author gratefully acknowledges the Geoscience Australia for the GIS data and Bureau of Meteorology, Australia for the time series rainfall and evaporation data sets and Department of Environment and Resource Management (DERM), Australia for the historical time series discharge data sets.

\section{REFERENCES}

[1] J. C. Refsgaard. (November 1997). Parameterisation, calibration and validation of distributed hydrological models. Journal of Hydrology [online]. 198(1-4). pp. 69-97. Available: http://www.sciencedirect.com/science/article/pii/S002216949603329X

[2] K. Beven (January 1989). Changing ideas in hydrology-the case of physically-based models. Journal of Hydrology [online]. 105(1). pp. 157-172. Available: http://www.sciencedirect.com/science/article/pii/0022169489901017

[3] J. C. Refsgaard and J. Knudsen. (July 1996). Operational validation and intercomparison of different types of hydrological models. Water Resources Research [online]. 32(7). pp. 2189-2202. Available: http://onlinelibrary.wiley.com/doi/10.1029/96WR00896/pdf

[4] S. A. Nielsen and E. Hansen. (1973). Numerical simulation of the rainfall runoff processes on a daily basis. Nordic Hydrology [Online]. 4(3), pp. 171-190. Available: http://www.iwaponline.com/nh/004/nh0040171.htm

[5] K. Havnø, M. N. Madsen and J. Dørge, "MIKE 11 - A generalized river modelling package," in Computer Models of Watershed Hydrology, V. P. Singh, Ed. Water Resources Publications, Colorado, 1995, pp. 733-782.

[6] Hydrologic Modeling System HEC-HMS: User's Manual: US Army Corps of Engineers, Hydrologic Engineering Center, Washington DC, USA, 2001

[7] R. G. Mein, E. M. Laurenson and T. A. McMahon, "Simple nonlinear model for flood estimation," Journal of the Hydraulics Division, Ed. New York, USA, American Society of Civil Engineers, 1974-2011, vol. 100 (Proc. Paper 10933), pp. 1507-18.

[8] A. Goyen and A. Aitken, "A regional stormwater drainage model," Hydrology Symposium, Sydney, Australia, 1976, pp. 40

[9] M. Sugawara, "Computer Models of Watershed Hydrology," in Computer Models of Watershed Hydrology, V. P. Singh, Ed. Colorado, 1995, pp. 165-214.

[10] R. J. C. Burnash, "Computer Models of Watershed Hydrology," in Computer Models of Watershed Hydrology, V. P. Singh, Ed. Colorado, 1995, pp. 311-365.

[11] P. O. Yapo, H. V. Gupta, and S. Sorooshian. (January 1998). Multi-objective global optimization for hydrologic models. Journal of Hydrology [Online]. 204(1-4). pp. 83-97. Available: http://www.sciencedirect.com/science/article/pii/S0022169497001078

[12] Y. Liu and F. Sun. (July 2010). Sensitivity analysis and automatic calibration of a rainfall-runoff model using multi-objectives. 
Ecological Informatics [Online]. 5(4). pp. 304-310. Available: http://www.sciencedirect.com/science/article/pii/S1574954110000580

[13] H. Madsen. (August 2000). Automatic calibration of a conceptual rainfall-runoff model using multiple objectives. Journal of Hydrology [Online]. 235(3), pp. 276-288. Available: http://www.sciencedirect.com/science/article/pii/S0022169400002791

[14] M. S. I. I. Amir, M. M. K. Khan, M. G. Rasul, R. H. Sharma, and F. Akram, "Rainfall, Temperature and Evaporation Trends in the Fitzroy Basin, Queensland, Australia," in $34^{\text {th }}$ Hydrology and Water Resources Symposium, Sydney, Australia, November 19-22, 2012. pp. 1484-1491.

[15] Handbook of Hydrology. D. R. Maidment, Ed. McGraw Hill, Inc. p3.19, New York, USA, 1993.

[16] User Guide: A modelling system for Rivers and Channels. Danish Hydraulic Institute, Denmark.

[17] C. J. Willmott, "On the validation of models," Physical Geography, vol 2, no. 2, pp. 184-194, 1981

[18] J. E. Nash and J. V. Sutcliffe. (April 1970). River flow forecasting through conceptual models part I - A discussion of principles. Journal of Hydrology [Online]. 10(3), pp. 282-290. Available: http://www.sciencedirect.com/science/article/pii/0022169470902556

[19] J. K. Lorup, J. C. Refsgaard and D. Mazvimavi. (March 1988) Assessing the effect of land use change on catchment runoff by combined use of statistical tests and hydrological modelling: Case studies from Zimbabwe. Journal of Hydrology [Online]. 205(3-4), pp. 147-163. Available: http://www.sciencedirect.com/science/article/pii/S0168117697003119

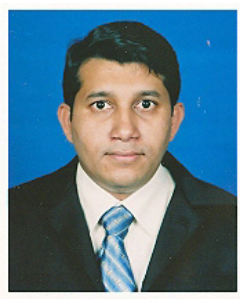

M. Sharif I. I. Amir was born in Bangladesh. He received the M.Sc. degree in Water Resources Development from Bangladesh University of Engineering \& Technology (BUET), Dhaka, Bangladesh, and B.Sc. Eng. (hons.) degree in Water Resources Engineering from the same University.

He has eight years of professional experience in the field of Water Resources Engineering. His technical expertise includes hydrological analysis; river hydraulics; river morphology; hydraulic design of cross drainage structure; hydrological and morpholog ical data collection, processing and analysis. He worked in several projects categorized as integrated water resources management, tidal river management, flood and drainage study, drainage design, morphological study and climate change impact on basin level. He has developed, calibrated and validated several flood, drainage, sediment transport, salinity and heat dispersion model for different client based assignments. Currently he is working towards $\mathrm{PhD}$ degree at Central Queensland University, Rockhampton, Australia. He has six publications in the area of river management.

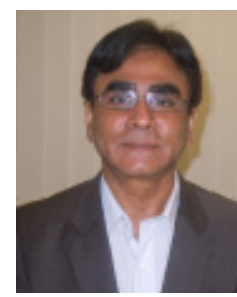

M. Masud K. Khan is employed by the Central Queensland University since 1990 and is currently a Professor in the School of Engineering and Technology. He received his MS from Moscow Institute of Petrochemical and Gas Industry in 1982. Subsequently he worked with the oil industry for 2 years. He then returned to a full-time $\mathrm{PhD}$ study, at the University of Sydney, which was awarded in 1990.

His research and teaching interests are in the area of fluid mechanics, rheology and sustainable energy technologies. He has a long history of working on industry collaborated projects and his works are well recognised both nationally and internationally. He has published over 185 research papers in journals and conferences including 5 book chapters and has spent three visiting professorial positions in the US and Canada working of various research projects. He is a member of the Institute of Engineers, Australia and an executive member of the Australian Society of Rheology (ASR).

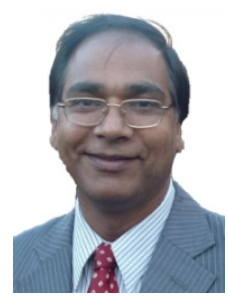

Mohammad G. Rasul was born in Bangladesh. He obtained his $\mathrm{PhD}$ in the area of energy, environment and thermodynamics from University of Queensland, Australia, in 1996. He received his Master of Engineering in energy technology from Asian Institute of Technology, Bangkok, Thailand, in 1990.

Currently, he is an Associate Professor in School of Engineering and Technology at Central Queensland University, Australia. He has published more than 240 research articles/papers both in reputed journals and refereed conferences including 8 book chapters, 2 edited books and 1 research book, one awarded paper in a refereed journal and two awarded papers at conferences. He has secured more than $\$ 2.5$ million research grant. He is recognised in professional communities which he has demonstrated through creating significant impact and the large number of citations by the relevant professionals, both nationally and internationally. His publications have been attracted significant interest with 430 citations and h-index of 12 .

Associate Professor Rasul has also made significant contributions in engineering education research and scholarship. He has edited a book on Developments in Engineering Education Standards: Advanced Curriculum Innovations published by IGI Global publisher in USA. His contributions to the profession and national and international community have been demonstrated through his varied roles and activities, such as membership of national and international technical, scientific and advisory committees, membership of different professional organizations and various organizing committees. He has been leading and contributing to the strategic research on Resource Industries and Sustainability in the area of energy, environment and thermodynamics.

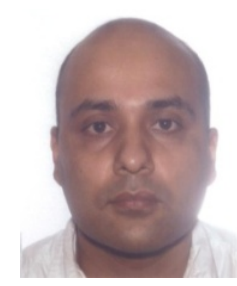

Raj H. Sharma received his B.E. and M.Sc. degrees from Tribhuvan University Nepal in 1999 and 2002 respectively and $\mathrm{PhD}$ degree from Kyoto University, Japan in 2006. He is working as a lecturer at School of Engineering and Technology, Central Queensland University, Australia from 2010. He was a Humboldt Fellow at TU Bergakademie Freiberg, Germany from 2007-2010. His research interests are flood, soil erosion and sediment transports.

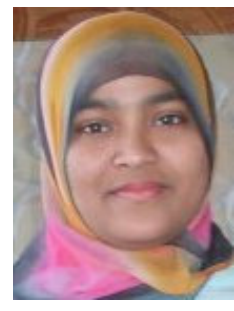

Fatema Akram was born in Bangladesh. She received both of the B.Sc. and M.Sc. degree in Water Resources Engineering from Bangladesh University of Engineering and Technology (BUET).

She has 7 years experience of working with Institute of Water Modelling (www.iwmbd.org). She has strong research interest in hydrologic and hydraulic modelling, groundwater modelling, water quality modelling, water resources assessment, sustainable water use, stormwater reuse and recycle techniques, geographic information systems etc. Currently she is working towards PhD degree at Central Queensland University, Rockhampton, Australia. She has two peer reviewed conference papers to her credit. 